\title{
Comparison of Rural and Urban Contraceptive Methods Preferences among Married Women in Malaysia, 2018
}

\author{
Nor Azah Samat ${ }^{1, *}$, Noor Azlin Muhammad Sapri ${ }^{2}$, Adzmel Mahmud ${ }^{2}$, Shazlyn Milleana Shaharudin ${ }^{1}$ \\ ${ }^{1}$ Department of Mathematics, Faculty of Science and Mathematics, Universiti Pendidikan Sultan Idris, 35900 Tanjong Malim, Perak, \\ Malaysia \\ ${ }^{2}$ Population and Family Research Division, National Population and Family Development Board, 50350 Kuala Lumpur, Malaysia
}

Received January 28, 2021; Revised April 9, 2021; Accepted May 30, 2021

\section{Cite This Paper in the following Citation Styles}

(a): [1] Nor Azah Samat, Noor Azlin Muhammad Sapri, Adzmel Mahmud, Shazlyn Milleana Shaharudin , "Comparison of Rural and Urban Contraceptive Methods Preferences among Married Women in Malaysia, 2018," Universal Journal of Public Health, Vol. 9, No. 4, pp. 173 - 180, 2021. DOI: 10.13189/ujph.2021.090402.

(b): Nor Azah Samat, Noor Azlin Muhammad Sapri, Adzmel Mahmud, Shazlyn Milleana Shaharudin (2021). Comparison of Rural and Urban Contraceptive Methods Preferences among Married Women in Malaysia, 2018. Universal Journal of Public Health, 9(4), 173 - 180. DOI: 10.13189/ujph.2021.090402.

Copyright $\bigcirc 2021$ by authors, all rights reserved. Authors agree that this article remains permanently open access under the terms of the Creative Commons Attribution License 4.0 International License

\begin{abstract}
Contraceptive use among women remains an important public health intervention. Imperatively, the equality of family planning access between rural and urban areas allows all women to have the same opportunities to receive family planning service towards better well-being of families. The study aims at comparing the family planning preferences among women aged 15 to 49 throughout Malaysia in 2018 according to the geographical locations of rural and urban areas. This is important for resource planning and allocation to the National Population and Family Development Board (NPFDB) clinic based on the locations. The data were collected from 49 NPFDB clinics throughout Malaysia. A total of 3668 married women aged 15 to 49 years used the family planning service in this NPFDB clinic in 2018. In this study, descriptive, Chi-Square, and logistic regression analyses were carried out to compare the patterns and preferences of contraceptive use. The results analysis shows that implant is the most popular method among all other contraceptive methods provided by the NPFDB clinics. Specifically, in both rural and urban areas, the three most popular contraceptive methods among married women in Malaysia in 2018 are implant, pill, and condom. Findings of the analysis based on the Chi-Square test show that age group, education levels, and different types of contraception methods were identified to have a significant association with the locations of either rural or urban areas. In conclusion, this study found that women who used implants as a method of contraceptives were often younger,
\end{abstract}

better educated, and lived in an urban area. Therefore, the family planning providers especially NPFDB clinics play a key role in providing information, educating couples, and promoting the use of different family planning methods so that better family well-being could be achieved.

Keywords Contraceptive Use, Family Planning, Contraceptive Method Preferences

\section{Introduction}

Family planning is defined as the ability to decide the right time and spacing to have children and how many children they want to have. This is important in reducing maternal and infant mortalities [1, 2, 3, 4], preventing unsafe abortion due to unwanted pregnancies [5], as well as for the financial management among women [6]. There are many types of family planning methods available in Malaysia [7] that include implant, contraceptive pills, Intrauterine Contraceptive Device (IUCD), condom, hormone injection, sterilization, and rhythm. The method chosen depends on a woman's body and is based on the doctor's advice as some methods have particular effects despite their efficacies. For instance, the contraceptive implant might not be a good option for women who had been treated for breast cancer or diagnosed with severe liver disease as these may prevent the implant from 
working [8]. Additionally, contraceptives that contain estrogen are not suitable for women who are: over 35 who smoke, very overweight and take certain medicines, and have certain medical conditions, while for women who cannot use contraceptives that contain estrogen, they may consider several other methods such as implant, injection, IUCD and progesterone-only pill [9].

Several studies had found that the popularity of family planning methods usages varied between rural and urban residents [10, 11, 12, 13]. In Malaysia, research that documents the contraceptive preferences of rural to urban women is scarce. This comparison is important in assessing health-related differences to detect if there is indicative of rural health disparities, as well as for the allocation of resources. Therefore, this study compares the family planning preferences among women aged 15 to 49 throughout Malaysia in 2018 according to the geographical locations, namely the rural and urban areas. The association between age groups, levels of education, and types of contraception method used were also investigated to identify whether these characteristics contribute to the preferences of contraceptive use between married women from rural or urban areas.

The finding of this study shows that the preference patterns of the contraceptive use by the residential locations, which are rural or urban areas, could give information to the authorities especially the NPFDB clinics to take further action to improve family well-being and accessibility especially in terms of the allocation of resources such as family planning stocks. These include various types of contraception methods, human resource allocation to the clinics, and suitable training or seminar for the public according to the locations of rural or urban areas.

\section{Methodology}

This study used a cross-sectional design. It was conducted in all 49 NPFDB Clinics throughout Malaysia for the calendar year of 2018. The selection criteria were married women between 15 and 49 years old, and new acceptors (new contraceptive users). Women who are unmarried, first-time users, and revisiting acceptors were excluded from the study.

The methodology used in this study was based on a descriptive analysis to compare the patterns of contraceptive use and determine the most popular contraceptive methods among women in Malaysia from rural and urban areas in 2018, specifically the clients of NPFDB clinics. Descriptive analysis is extremely valuable because it can provide an in-depth description of the phenomenon, and in this study, it was used to discover the pattern of contraceptive method preferences between women who lived in rural and urban areas. In addition, Chi-Square and logistic regression analyses were also used to determine the association between age groups, levels of education, and types of contraception method use based on the residential locations of the new acceptors, either from rural or urban areas.

\subsection{The Data Set}

This study builds on a secondary data analysis. The data were provided by the NPFDB, drawn from the Reproductive and Health Information System (RHIS) with technical assistance from the Human Reproductive Division and Information Management Division, NPFDB. The information of new acceptors provided by the NPFDB for this study includes the types of family planning method, age, educational level, and location of residence (rural or urban).

\subsection{The location of NPFDB Clinics}

There are 49 NPFDB clinics throughout Malaysia known as Nur Sejahtera Clinics. All these 49 clinics are located in the urban areas and are an initiative by the NPFDB to expand the scope of existing services to help women and men towards a more healthy and prosperous life. Reproductive health services to be provided include Reproductive Health Screening Packages, Family Planning, Reproductive Cancer Screening, Menopause Management, and Comprehensive laboratory test.

Nur Sejahtera Clinics provides family planning services for new acceptors who are typically defined as new users of contraceptives or new clients to the clinic. The NPFDB offers a 'cafeteria' type of service to ensure clients receive the widest possible choices of safe, effective, affordable, and acceptable methods at all its 49 clinics throughout the country [14].

\section{Results and Analysis}

\subsection{Demographic Analysis}

\subsubsection{New Acceptors by State}

Figure 1 shows the total number of new acceptors of contraceptives according to various types of contraceptive methods among women aged 15 to 49, who had attended the NPFDB clinics in 2018 for all 16 states in Malaysia. There were 3,668 clients, in which the state of Pulau Pinang had the highest number of clients which is 528 women, followed by Kuala Lumpur with 449 clients and Selangor with 429 clients. Additionally, Labuan had the lowest number of clients of only 9 women.

Overall, the most popular method in most states was implant in Johor (33\%), Kelantan (52\%), Kuala Lumpur (48\%), Labuan (33\%), Pahang (43\%), Selangor (45\%), Terengganu (66\%), followed by pill in four states including Melaka (29\%), Negeri Sembilan (25\%), Perlis (52\%) and Sabah (32\%), condom in Kedah (30\%), Perak (38\%) and Sarawak (31\%), and hormone injection in Putrajaya (38\%). Surprisingly, the most popular method in Pulau Pinang was 
'others' (59\%). Here, 'others' refers to contraceptive methods including rhythm, withdrawal, hormone patch, cream, gels, contraceptive ring, diaphragm, foam, breastfeeding, and traditional methods such as taking medicines made from roots, leaves, shoots, or fruit trees, and massage methods [15].

Table 1. Percentage of New Acceptors by Family Planning Methods in 2018

\begin{tabular}{|c|c|c|}
\hline Method & Total & Percentage (\%) \\
\hline Condom & 621 & 17 \\
\hline Injection & 455 & 12 \\
\hline Implant & 1036 & 28 \\
\hline IUCD & 386 & 11 \\
\hline Pill & 639 & 17 \\
\hline Others & 531 & 15 \\
\hline
\end{tabular}

Overall, it can be seen from Table 1 that the contraceptive implant was the most frequently used method ( $n=1036 ; 28 \%$ ) in 2018, followed by contraceptive pill ( $n=639,17 \%)$ and condom $(n=621,17 \%)$. The 'others' method ( $n=531,15 \%$ ) was fourth, followed by hormone injection ( $n=455,12 \%)$ and IUCD $(n=386,11 \%)$.

\subsubsection{New Acceptors by Age Group}

Figure 2 depicts the number of contraceptives used among women based on age groups and residence locations. In this study, age groups were divided into three categories of 25 years old and below, 26 to 39 years old, and 40 years old and above [16]. It can be seen that the majority of women were from the urban areas (89\%) as compared to the rural areas (11\%). Most women attending the NPFDB clinics were from the urban areas and aged between 26 and 39 (75\%). This is followed by women aged 25 and below (14\%), and women aged between 40 and above (11\%). Similarly, most women from the rural areas were aged between 26 to 39 (73\%), followed by women aged 25 and below (19\%), and women aged 40 and above (8\%).

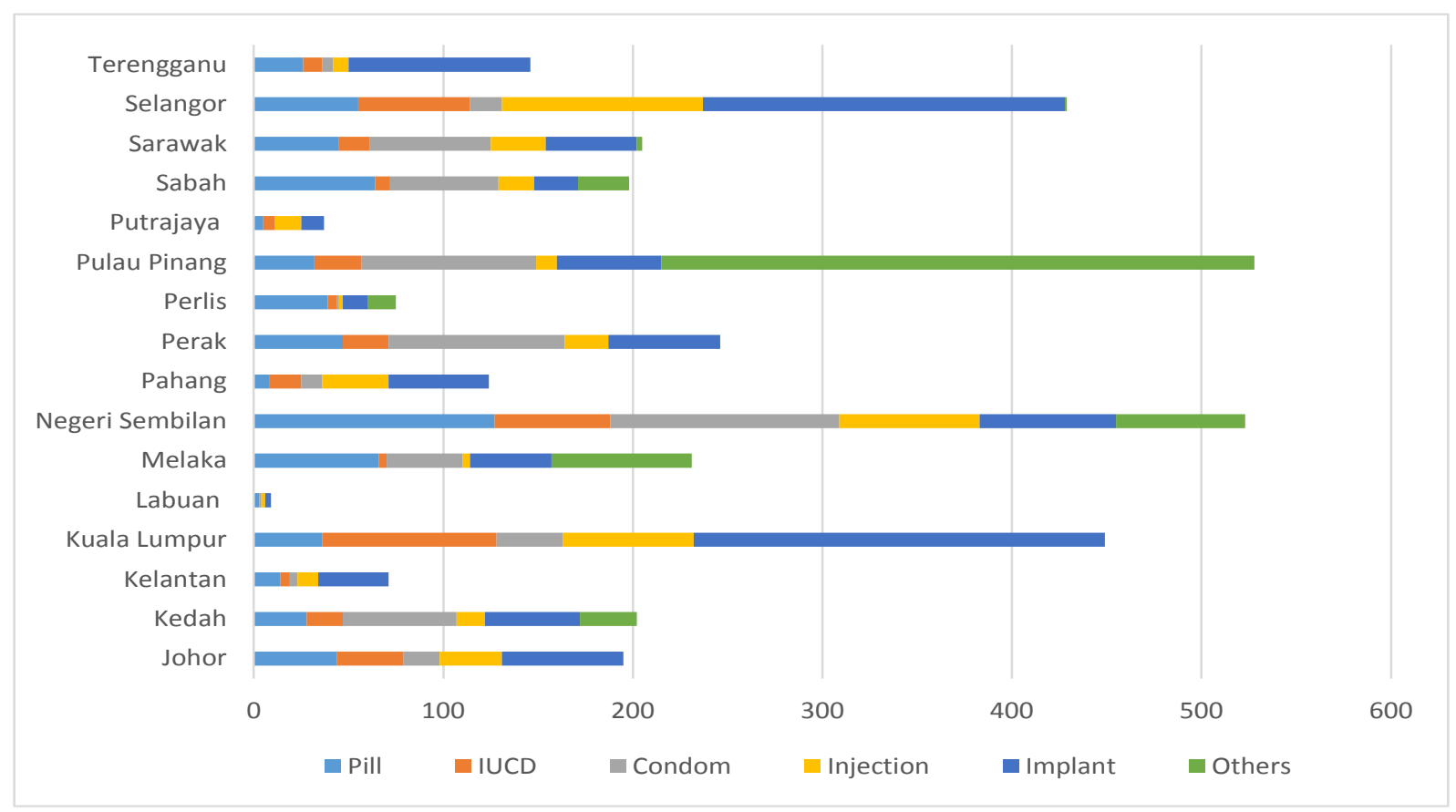

Figure 1. Number of New Acceptors by States and Contraceptive Methods in 2018

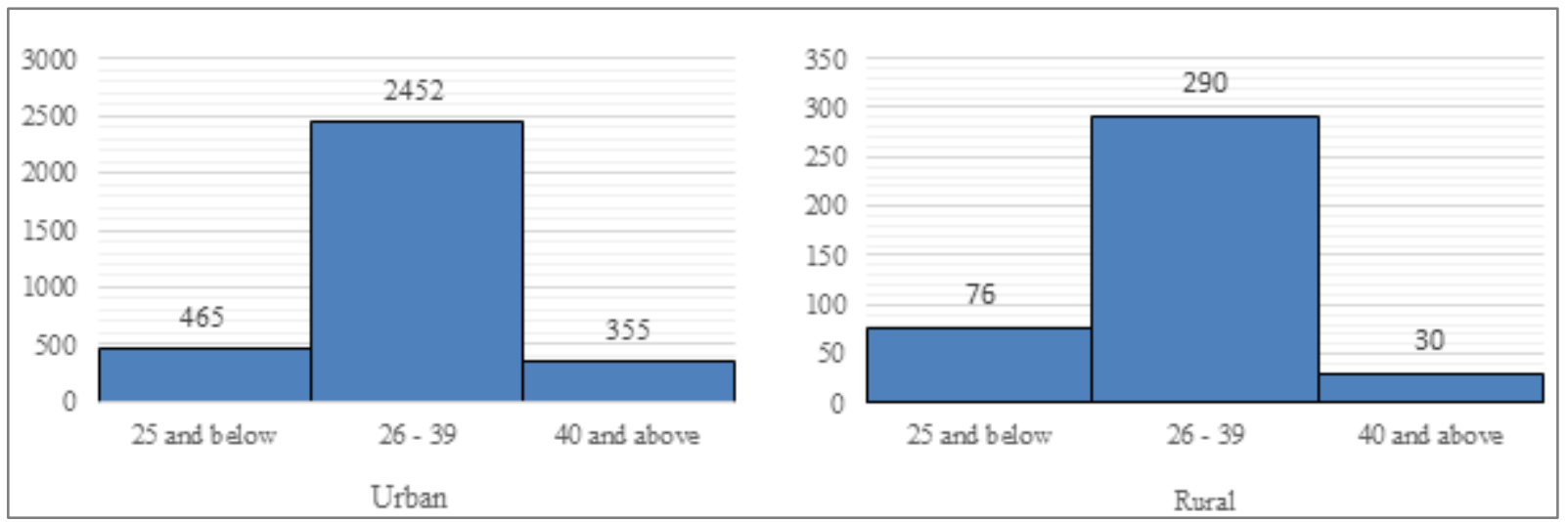

Figure 2. Number of New Acceptors by Age Group for Urban and Rural Areas 


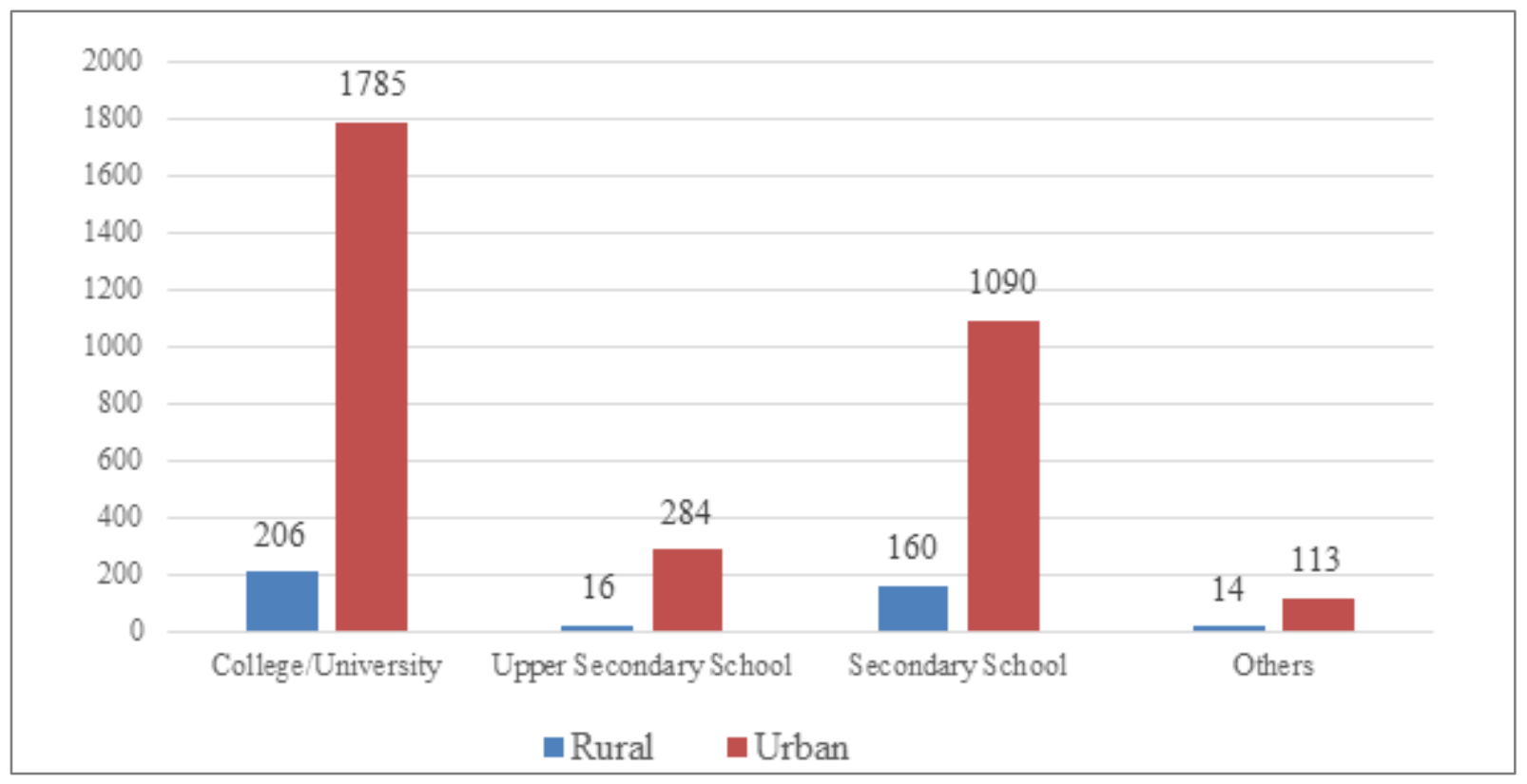

Figure 3. Number of New Acceptors by Education Levels for Rural and Urban Areas

\subsubsection{New Acceptors by Education Levels}

Figure 3 shows a bar graph of the number of contraceptive used by women from both rural and urban areas according to the levels of education. It can be seen that the majority of women from the urban areas had education from college/university (55\%) and secondary school (33\%). Similarly, women from the rural areas also had education from college/university (52\%) and secondary school (40\%). Here, 'others' education level refers to either primary school, pre-school, no education or unknown.

\subsection{Comparison of Contraceptive Method Preferences in Rural and Urban Areas}

This section divides the discussion on the comparison of contraceptive method preferences between women from rural and urban areas according to the descriptive analysis, Chi-Square analysis, and logistic regression. The descriptive analysis was used to analyze the pattern of contraceptive use preferences, the Chi-Square was used to analyze the association of the three characteristics identified with the locations either rural or urban areas, whilst the logistic regression was used to further investigate on the characteristics that explain the contraceptive use among women from urban or rural areas.

\subsubsection{Descriptive Analysis}

A comparison of the six types of contraceptive methods used by married women in rural and urban areas of 16 states in Malaysia found out that most clients who came to Nur Sejahtera Clinics were from urban areas $(n=3272)$ compared to rural areas $(n=396)$.
Table 2. Percentage of New Acceptors by States and Location (Rural or Urban Areas)

\begin{tabular}{|l|ll|lr|}
\hline \multicolumn{1}{|c|}{ States } & \multicolumn{2}{|c|}{$\begin{array}{c}\text { Contraceptive } \\
\text { Methods } \\
\text { Preference } \\
\text { (Urban) }\end{array}$} & \multicolumn{2}{c|}{$\begin{array}{c}\text { Contraceptive } \\
\text { Methods Preference } \\
\text { (Rural) }\end{array}$} \\
\hline (1) Pulau Pinang & Others & $\mathbf{( 5 4 \% )}$ & Others & $(96 \%)$ \\
(2) N. Sembilan & Pills & $(24 \%)$ & Pills & $(30 \%)$ \\
(3) K.Lumpur & Implant & $(48 \%)$ & Implant & $(45 \%)$ \\
(4) Selangor & Implant & $(45 \%)$ & Implant & $(40 \%)$ \\
(5) Perak & Condom & $(40 \%)$ & Implant & $(43 \%)$ \\
(6) Melaka & Others & $(31 \%)$ & Others & $(39 \%)$ \\
(7) Sarawak & Condom & $(28 \%)$ & Condom & $(54 \%)$ \\
(8) Kedah & Implant & $(32 \%)$ & Condom & $(39 \%)$ \\
(9) Sabah & Pills & $(34 \%)$ & Condom & $(36 \%)$ \\
(10) Johor & Implant & $(33 \%)$ & Implant & $(30 \%)$ \\
(11) Terengganu & Implant & $(64 \%)$ & Implant & $(71 \%)$ \\
(12) Pahang & Implant & $(45 \%)$ & Injection & $(50 \%)$ \\
(13) Perlis & Pills & $(70 \%)$ & Others & $(68 \%)$ \\
(14) Kelantan & Implant & $(43 \%)$ & Implant & $(65 \%)$ \\
(15) Putrajaya & Injection & $(42 \%)$ & Implant & $(100 \%)$ \\
(16) Labuan & Implant & $(33 \%)$ & \multicolumn{2}{|c}{ Not available } \\
\hline
\end{tabular}

From Table 2, in rural areas, implant had been the most popular contraceptive method in seven states including Johor ( $n=6,30 \%)$, Kelantan $(n=20,65 \%)$, Kuala Lumpur $(n=5,45 \%)$, Perak ( $n=10,43 \%)$, Putrajaya $(n=4,100 \%)$, Selangor $(n=2,40 \%)$ and Terengganu $(n=22,71 \%)$. This is followed by the condom method as the most popular in three states of Kedah $(n=28,39 \%)$, Sabah $(n=13,36 \%)$ and Sarawak $(n=13,54 \%)$, and and the others method in Melaka ( $\mathrm{n}=9,39 \%)$, Perlis $(\mathrm{n}=13,68 \%)$ and Pulau Pinang $(\mathrm{n}=54,96 \%)$. Furthermore, contraceptive pill was the most popular in Negeri Sembilan ( $n=8,30 \%)$ whilst the most popular contraceptive method in Pahang rural area was hormone injection $(n=7,50 \%)$. No cases recorded in Labuan as there was no data for the rural areas. 
Similarly, in urban areas, implant was the most popular in eight states, namely Johor $(\mathrm{n}=58,33 \%)$, Kedah $(\mathrm{n}=41$, $32 \%)$, Kelantan ( $\mathrm{n}=17,43 \%)$, Kuala Lumpur $(\mathrm{n}=212,48 \%)$, Labuan $(n=3,33 \%)$, Pahang $(n=49,45 \%)$, Selangor $(n=189$, $45 \%)$ and Terengganu $(n=74,64 \%)$ while contraceptive pill was the most popular one in three states including Negeri Sembilan $(n=119,24 \%)$, Perlis $(n=39,70 \%)$ and Sabah $(n=55,34 \%)$. Moreover, condom was the most popular contraceptive method in two states that are Perak $(n=89,40 \%)$ and Sarawak ( $n=51,28 \%)$, whilst others was the most popular method in Melaka ( $\mathrm{n}=64,31 \%$ ) and Pulau Pinang ( $\mathrm{n}=255,54 \%)$. Lastly, hormone injection was the most popular in Putrajaya ( $\mathrm{n}=14,42 \%)$.

Overall, the three most popular methods used among married women in both rural and urban areas in Malaysia were implant, pill, and condom. The IUCD was found to be a less popular method in 2018. Due to the popularity similarity between the rural and urban areas, it can be said that there was no obvious rural health disparities.

In comparison, many studies on contraceptive preference showed that different countries have different types of contraceptive preference. For instance, a study by Thulaseedharan[17] on contraceptive use and preferences in Kerala, India revealed that the most common method used by young married women in Kerala was female sterilization compared to other states in India. Additionally, according to Huda[18], in her study related to contraceptive practices among married women of reproductive age in Bangladesh, oral pill was the most widely-used method, followed by injections, condoms, female sterilization, male sterilization, implants, and IUCD. Meanwhile, a study conducted by Ukegbu[19] on contraceptive method preferences, use, and satisfaction among women of reproductive age highlighted that the most preferred contraceptive in Umuahia, Abia State in Nigeria was the condom.

Furthermore, another study by Zhang[20] had discovered that female sterilization was the first choice among married women in Anhui Province of China, followed by the intrauterine device (IUD). However, in a study conducted by de Irala[21] on the choice of birth control methods among European women highlight, oral contraceptives were mainly used in Germany, France, and Sweden, and condoms in the United Kingdom and Romania. Meanwhile, Sweden showed the highest use of intrauterine devices.

The differences in contraceptive use preferences between different countries might be shaped by the surrounding socioeconomic and cultural environment. These include ethnic, cultural, religious diversity, and health facilities provided by the clinic [22].

\subsubsection{Chi-Square Analysis}

In this study, the Chi-Square test was used to assess the association between the current use of contraception for married women from rural and urban areas, and their associated characteristics.

From Table 3, it can be seen that women from rural areas in the age group of 20 to 29 years and women from urban areas in the age group of 30 to 39 years used contraceptives considerably more than other age groups in the categories. This study had also elucidated that the contraceptive use was higher among women from urban areas for every level of education than women from rural areas. Furthermore, the majority of women from both rural and urban areas preferred to use contraceptive implants compared to other contraception methods offered by the NPFDB clinics.

The results of the Chi-Square analysis of association in Table 3 also show that age groups $(p<0.008)$, education levels $(p<0.002)$, and types of contraception method use $(p<0.001)$ were significantly associated with the locations of new acceptors from either rural or urban areas. This means that these characteristics contribute to the preferences of contraceptive use between married women from either rural or urban areas.

Table 3. Chi-Square Analysis of Association

\begin{tabular}{|c|c|c|c|c|c|}
\hline & \multicolumn{2}{|c|}{ Rural } & \multicolumn{2}{|c|}{ Urban } & $p$-value \\
\hline $\begin{array}{ll}\text { - } & 25 \text { and below } \\
\text { - } & 26-39 \\
\text { - } & 40 \text { and above } \\
\end{array}$ & $\begin{array}{c}76 \\
290 \\
30 \\
\end{array}$ & $\begin{array}{l}(2.1 \%) \\
(7.9 \%) \\
(10.8 \%) \\
\end{array}$ & $\begin{array}{r}465 \\
2452 \\
355 \\
\end{array}$ & $\begin{array}{c}(12.7 \%) \\
(66.8 \%) \\
(9.7 \%) \\
\end{array}$ & 0.008 \\
\hline \begin{tabular}{ll} 
& \multicolumn{1}{c}{ Education levels } \\
- & College/ University \\
- & Upper Secondary School \\
- & Secondary School \\
\end{tabular} & $\begin{array}{r}206 \\
16 \\
160 \\
14 \\
\end{array}$ & $\begin{array}{l}(52.02 \%) \\
(4.04 \%) \\
(40.40 \%) \\
(3.54 \%) \\
\end{array}$ & $\begin{array}{r}1784 \\
284 \\
1091 \\
113 \\
\end{array}$ & $\begin{array}{l}(54.52 \%) \\
(8.68 \%) \\
(33.34 \%) \\
(3.45 \%) \\
\end{array}$ & 0.002 \\
\hline \begin{tabular}{ll} 
& \multicolumn{1}{c}{ Contraception Methods } \\
- & Implant \\
- & IUCD \\
- & Condom \\
- & Injection \\
- & Pill \\
\end{tabular} & $\begin{array}{l}105 \\
33 \\
67 \\
37 \\
68 \\
86 \\
\end{array}$ & $\begin{array}{r}(27 \%) \\
(8 \%) \\
(17 \%) \\
(9 \%) \\
(17 \%) \\
(22 \%)\end{array}$ & $\begin{array}{l}931 \\
353 \\
554 \\
418 \\
571 \\
445 \\
\end{array}$ & $\begin{array}{l}(28 \%) \\
(11 \%) \\
(17 \%) \\
(13 \%) \\
(17 \%) \\
(14 \%)\end{array}$ & 0.001 \\
\hline
\end{tabular}




\subsubsection{Binary Logistic Regression}

In this study, binary logistic regression was used to further assess the multiple characteristics that explain new acceptors attending the NPFDB clinics, from either urban or rural areas. Here, the response variable considered was the stratum or location where the new acceptors came from, in which the response can be expressed as ' 1 ' for women from the urban areas, and ' 0 ' for women from the rural areas. The independent variables used in this study include the age, education levels, and the types of contraceptive methods used.

Therefore, based on [23], the binary logistic regression equations in this study can be written as follows:

$$
\begin{gathered}
y=\beta_{0}+\beta_{1} X_{1, i}+\beta_{2} X_{2, i}+\beta_{3} X_{3, i} \\
y=\log _{e}\left(\frac{1-p}{p}\right)=\operatorname{logit}(p) \\
p=\frac{e^{y}}{1+e^{y}}
\end{gathered}
$$

where $y$ is the a linear combination function of the explanatory variables representing a linear relationship, the variables $X_{1, i}, X_{2, i}$, and $X_{3, i}$ are the explanatory variables, namely the associated characteristics, and the parameters $\beta_{0}, \beta_{1}, \beta_{2}$, and $\beta_{3}$ are the regression coefficients to be estimated. Here, $p$ refers to the probability of occurrence ( $1=$ urban, $0=$ rural), and function $y$ is represented as $\operatorname{logit}(p)$.

Table 4 shows the results of the binary logistic regression of a full model that depicts the coefficients associated with each of the independent variables entered into the logistic regression model, significance level ( $p$-value), Wald statistic for the odds ratio, and respective confident intervals. From Table 4, it can be seen that the overall variables, which are age group $(p<0.038)$, education levels $(p<0.011)$, and contraceptive methods $(p<0.007)$, are statistically significant. This means that the contraceptive use among women from the urban areas are significantly explained by these three characteristics as a whole. However, the age group category of 26 to 39 years old, and the education levels category of college/university and secondary school is fairly insignificant. Therefore, these categories will be removed from the model. Hence, the logistic regression equation from Table 4 can be written as follows:

$$
\begin{gathered}
\text { Logit }(p)=1.404+0.573(\text { Age })+0.823(\text { Education })+ \\
+0.436(\text { Implant })+0.451(\text { IUCD })+ \\
+0.423(\text { Condom })+0.727(\text { Injection })+0.591(\text { Pill })
\end{gathered}
$$

In terms of age, it can be seen that the odds of married women aged 26 to 39 to use a contraceptive are 1.3 times more likely to live in urban areas than those aged 25 years and below, which is the reference category. Similarly, the odds of women aged 40 and above to use a contraceptive are 1.8 times more likely to live in urban areas than those aged 25 years and below. The result shows that the odds of using contraception among women from urban areas increase as the age of married women increases.

Furthermore, the odds of using contraceptives among women from urban with education from college/university, and upper secondary schools are 1.1, and 2.3 times higher than the odds of using contraceptive among women from urban with others education levels, respectively. In contrast,

\begin{tabular}{|c|c|c|c|c|c|c|c|}
\hline \multirow{2}{*}{ Variables } & \multirow{2}{*}{$\beta$} & \multirow{2}{*}{ Wald } & \multirow{2}{*}{$\mathrm{df}$} & \multirow{2}{*}{ Sig. } & \multirow{2}{*}{$\operatorname{Exp}(\boldsymbol{\beta})$} & \multicolumn{2}{|c|}{$95 \%$ C.I. for $\operatorname{Exp}(\beta)$} \\
\hline & & & & & & Lower & Upper \\
\hline Constant & 1.404 & 18.846 & 1 & 0.000 & 4.072 & & \\
\hline $\begin{array}{ll} & \text { Age Group } \\
\text { - } & 25 \text { and below } \\
\text { - } & 26-39 \\
\text { - } & 40 \text { and above } \\
\end{array}$ & $\begin{array}{c}\text { Reference } \\
0.251 \\
0.573 \\
\end{array}$ & $\begin{array}{l}6.518 \\
3.022 \\
6.150 \\
\end{array}$ & $\begin{array}{l}2 \\
1 \\
1 \\
\end{array}$ & $\begin{array}{l}\mathbf{0 . 0 3 8} \\
0.082 \\
\mathbf{0 . 0 1 3} \\
\end{array}$ & $\begin{array}{l}1.285 \\
1.773 \\
\end{array}$ & $\begin{array}{l}0.969 \\
1.128 \\
\end{array}$ & $\begin{array}{l}1.706 \\
2.789 \\
\end{array}$ \\
\hline \begin{tabular}{ll} 
& \multicolumn{1}{c}{ Education Levels } \\
- & College/ University \\
- & Upper Secondary School \\
- & Secondary School \\
- & Others \\
\end{tabular} & $\begin{array}{c}0.071 \\
0.823 \\
-0.076 \\
\text { Reference }\end{array}$ & $\begin{array}{c}11.134 \\
0.057 \\
4.578 \\
0.065 \\
\end{array}$ & $\begin{array}{l}3 \\
1 \\
1 \\
1\end{array}$ & $\begin{array}{l}\mathbf{0 . 0 1 1} \\
0.811 \\
\mathbf{0 . 0 3 2} \\
0.799 \\
\end{array}$ & $\begin{array}{l}1.073 \\
2.278 \\
0.927\end{array}$ & $\begin{array}{l}0.600 \\
1.072 \\
0.517\end{array}$ & $\begin{array}{l}1.921 \\
4.844 \\
1.662\end{array}$ \\
\hline $\begin{array}{ll}\text { - } & \text { Contraceptive Methods } \\
\text { - } & \text { Implant } \\
\text { - } & \text { IUCD } \\
\text { - } & \text { Condom } \\
\text { - } & \text { Injection } \\
\text { - } & \text { Pill } \\
\end{array}$ & $\begin{array}{c}0.451 \\
0.591 \\
0.423 \\
0.727 \\
0.436 \\
\text { Reference }\end{array}$ & $\begin{array}{c}15.877 \\
7.794 \\
7.127 \\
5.771 \\
11.903 \\
6.166\end{array}$ & $\begin{array}{l}5 \\
1 \\
1 \\
1 \\
1 \\
1\end{array}$ & $\begin{array}{l}0.007 \\
0.005 \\
0.008 \\
0.016 \\
0.001 \\
0.013\end{array}$ & $\begin{array}{l}1.569 \\
1.806 \\
1.526 \\
2.069 \\
1.546\end{array}$ & $\begin{array}{l}1.144 \\
1.170 \\
1.081 \\
1.369 \\
1.096\end{array}$ & $\begin{array}{l}2.153 \\
2.786 \\
2.155 \\
3.127 \\
2.182\end{array}$ \\
\hline
\end{tabular}
the odds of using contraceptive among women with education from secondary schools are 0.9 less likely to live in urban areas compared to women with others education levels.

Table 4. Binary Logistic Regression 
Lastly, the odds of women using the contraceptive pill are 1.5 more likely to live in urban areas compared to those women that use others contraceptive method. Likewise, the odds of women living in urban areas and using contraceptive implant, condom, injection, and IUCD are 1.6, 1.5, 2.1, and 1.8 times higher than those women who use others contraceptive method, respectively.

\section{Conclusions}

Family planning contributes to the reduction of maternal and infant mortality not only in Malaysia but also worldwide. Every woman in the world needs knowledge and understanding of the need for family planning for the better well-being of families regardless of where they live in the urban or rural areas. In this study, a comparison of family planning preferences was made among women aged 15 to 49 throughout Malaysia in 2018 according to the geographical locations, which are rural and urban areas. Overall, women from both rural and urban areas preferred contraceptive implants, pills, and condoms, compared to the other family planning methods offered by NPFDB clinics. Findings of the analysis based on the Chi-Square test show that age group, education levels, and different types of contraception methods were identified to have a significant association with the locations of either rural or urban areas. Further analysis based on the logistic regression also shows that these three associated characteristics had significantly explained the contraceptive use among women from urban areas compared to the rural areas. Some areas were recorded to have the highest use of certain family planning methods due to greater availability and accessibility of the methods. Although no obvious rural-urban differences in terms of age group and level of education, rural clients reported more barriers to assessing the contraceptives compared to urban clients. Generally, this study discovered that women who attended the NPFDB clinic mostly preferred implant as a method of contraceptives among all other family planning methods. They were often young aged between 26 and 39, better educated with the majority being college/university graduates, and live in an urban area. These findings are important for the NPFDB as studies on contraceptives according to rural or urban areas are scarce in Malaysia.

\section{Acknowledgements}

The authors acknowledge Universiti Pendidikan Sultan Idris for their financial support in respect of this study, and the National Population and Family Development Board (NPFDB) for granting an access to the data.

\section{REFERENCES}

[1] Degfie T. T., African Population and Health Research Center, "Why family planning matters for maternal deaths and child?”, 2017. https://theconversation.com/why-family-plan ning-matters-for-maternal-deaths-and-child-survival-80618. DOI: https://doi.org/10.4103/jfmpc.jfmpc_390_19.

[2] Chola L., McGee S., Tugendhaft A., Buchmann E., and Hofman K., "Scaling Up Family Planning to Reduce Maternal and Child Mortality: The Potential Costs and Benefits of Modern Contraceptive Use in South Africa”, PLOS ONE, 2015. DOI: https://doi.org/10.1371/journal.pon e.0130077

[3] Ahmed S., Li Q., Liu L., and Tsui A.O., "Maternal deaths averted by contraceptive use: an analysis of 172 countries", The Lancet, vol. 380, no. 9837, pp. 111-125, 2012. DOI: https://doi.org/10.1016/S0140-6736(12)60478-4

[4] Winikoff B. and Sullivan M., "Assessing the role of family planning in reducing maternal mortality”, PubMed: Studies in Family Planning, vol. 18, no. 3, 1987.

[5] Eremutha Awasighe Francis, Okosun Onaburekhalen Thankgod, Gabriel Veronica Chizoba, Diakpomrere Oghenevweta Vincent (2019). Evidence Based Abortion Stigma Reduction Using Radio Drama in Nigeria. Universal Journal of Public Health, 7(3), 90 - 102. DOI: 10.13189/ujph.2019.070302.

[6] Sultan S., "The Effects of Education, Poverty, and Resources on Family Planning in Developing Countries”, Clinics in Mother and Child Health, vol. 15, no. 1, 2018. DOI: 10.4172/2090-7214.1000289

[7] Malaysia. Ministry of Health, “Family Planning”, 2020. http://www.myhealth.gov.my/en/family-planning/

[8] Australia. "Family Planning Victoria”, 2020. https://www.fpv.org.au/for-you/contraception/long-acting-re versible-contraception-larc/contraceptive-implant-implanon

[9] United Kingdom: National Health Service, "Which method of contraception suits me?: Your Contraception Guide”, 2020. https://www.nhs.uk/conditions/contraception/whichmethod-suits-me/

[10] Uddin M. M., Kabir M., Choudhury S.R., Ahmed T., and Bhuyan M.R., "Rural-Urban Differential in Contraceptive Use Status in Malaysia”, PubMed: Rural Demography, vol. 12, no. 1-2. pp.1-20, 1985.

[11] Tober A., Lutfiyya M.N., Mabasa Y., Meena H., McGrath C., Brady S., Aguero C., Bales R., and King M., "Comparison of Contraceptive Choices of Rural and Urban US Adults Aged 18 - 55 Years: An Analysis of 2004 Behavioural Risk Factor Surveillance Data”, PubMed: Rural and Remote Health, vol. 9, no. 3, pp. 1186, 2009.

[12] Bogale, B., Wondafresh, M, Tilahun, T., and Girma E., "Married Women Decision Making Power on Modern Contraceptive Use in Urban and Rural Southern Ethiopia”, BMC Public Health, vol. 11, pp. 342, 2011. DOI: https://doi.org/10.1186/1471-2458-11-342.

[13] Geske S., Quevillon R., Johnson C.S., and Hansen K., "Comparison of Contraceptive Use between Rural and Urban Teens”, Journal of Paediatric and Adolescent Gynaecology, vol. 29, no. 1, pp. 33-41, 2016. 
DOI:10.1016/j.jpag.2015.06.002.

[14] Ahmad N, Tey N, Kamarul Zaman K, Muhd Sapri N, Abdul Manaf N, Yeoh Y., "Status of family planning in Malaysia”, Family Planning in Asia and Pacific Region: National Population and Family Development Board (NPFDB) Bangkok, Thailand, pp. 1-29, 2010.

[15] Malaysia. National Population and Family Development Board, “Manual Penemubual KPKM-5”, 2014.

[16] Malaysia. "Perangkaan Program Perkhidmatan Perancangan Keluarga Kebangsaan”, 2012

[17] Thulaseedharan, J.V., "Contraceptive use and preferences of young married women in Kerala, India”, Journal of Contraceptive, vol. 9, pp. 1-10, 2018.

[18] Huda, F.A, Robertson, Y., Chowdhuri, S., Sarker, B.K., Reichenbach, L., and Somrongthong, R., "Contraceptive practices among married women of reproductive age in Bangladesh: a review of the evidence”, Reproductive Health, vol. 14, no. 69, 2017.

[19] Ukegbu, A.U., Onyeonoro U.U., Nwokeukwu H.I., and
Okafor, G.O.C., “Contraceptive Method Preferences, Use and Satisfaction among Women of Reproductive Age (15-49 Years) in Umuahia, Abia State, Nigeria”, Journal of Contraceptive Studies, vol. 3, no. 16, 2018.

[20] Zhang, X.J., Wang, G.Y, Shen, Q., Yu, Y.L, Sun, Y.H., Yu, G.B., Zhao, D., and Ye D.Q., (2009), "Current status of contraceptive use among rural married women in Anhui Province of China”, An International Journal of Obstetrics and Gynaecology, pp. 1640 -1645, 2009.

[21] de Irala, J., Osorio, A., Carlos, S. and López-del Burgo C., "Choice of birth control methods among European women and the role of partners and providers", Contraception, vol. 84, pp. 558-564, 2011.

[22] Agonnoude T. Maurice, Houeto S. David , Sambieni N. Emmanuel , Adoukonou T. Thierry A , Aguessy Constant (2020). Impact of Performance-Based Financing on Health Facilities Performance in Family Planning. Universal Journal of Public Health, 8(1), 15 - 22. DOI: 10.13189/ujph.2020.080102.

[23] Homers, D.W., and Lemeshow, S., "Applied Logistic Regression”, New York: Wiley \& Sons, 2000. 